\title{
Reactions of $\mathrm{OH}$ and $\mathrm{Cl}$ with isopropyl formate, isobutyl formate, n-propyl
}

\section{isobutyrate and isopropyl isobutyrate}

Y.J. Zhang ${ }^{\text {a,b }}$, P. Liang ${ }^{\text {a,c }}$, Z.H. Jiang ${ }^{\text {a }}$, M. Cazaunau ${ }^{\text {a }}$, V. Daële ${ }^{\text {a }}$, Y.J. Mu ${ }^{\text {c }}$, A. Mellouki ${ }^{\text {a,d,* }}$

a Institut de Combustion, Aérothermique, Réactivité et Environnement (ICARECNRS)/OSUC, 1C Avenue de la Recherche Scientifique, 45071 Orléans, France

${ }^{\mathrm{b}}$ Chinese Research Academy of Environmental Science (CRAES), Beijing 100012

${ }^{\mathrm{c}}$ Research Center for Eco-Environmental Sciences (RCEES), Chinese Academy of Sciences, Beijing 100085

${ }^{\mathrm{d}}$ Environment Research Institute/School of Environmental Science \& Engineering, Shandong University, Shandong 250100

* Corresponding author:

A. Mellouki, ICARE-CNRS, 1C Avenue de la Recherche Scientifique, 45071 Orléans Cedex 02, France (Fax: (33) 238 696004, e-mail: mellouki@cnrs-orleans.fr) 


\begin{abstract}
:
The rate coefficients for the reactions of $\mathrm{OH}$ with isopropyl formate, isobutyl formate, npropyl isobutyrate and isopropyl isobutyrate have been determined using both absolute and relative methods. The relative rate method has been also used to measure the room temperature rate coefficient for the reaction of $\mathrm{Cl}$ with the same esters. In addition, a series of runs conducted on the $\mathrm{OH}$-initiated oxidation of isopropyl formate, isobutyl formate and npropyl isobutyrate showed the formation of acetone from the three reactions. The formation of propanal was also observed for n-propyl isobutyrate.
\end{abstract}

Keywords: $\mathrm{OH}$ radicals, $\mathrm{Cl}$ atoms, isopropyl formate, isobutyl formate, $\mathrm{n}$-propyl isobutyrate, isopropyl isobutyrate. 


\section{INTRODUCTION}

Esters are widely used as alternative solvents and additives in a number of industries. They are also emitted into the atmosphere from biogenic sources such as vegetation and produced within the atmosphere from the oxidation of other volatile organic compounds such as ethers. Despite their low toxicity, the atmospheric degradation of esters may lead to the production of more toxic species. With the increase of their uses, it is of importance to assess their contribution to photo-oxidants formation in urban air masses, which requires detailed kinetic and mechanistic informations on their atmospheric oxidation processes.

Although reactions with $\mathrm{OH}$ radicals are considered to be the dominant tropospheric removal process for esters, their reactions with $\mathrm{Cl}$ atoms are not negligible and can be important and ubiquitous in coastal areas and marine boundary layer. Indeed, relatively high $\mathrm{Cl}$ atoms concentrations have been reported by different studies [1] indicating that the reactions of $\mathrm{Cl}$ can trigger a fast oxidation of volatile organic compounds and hence compete with the $\mathrm{OH}$ reactions. The other possible atmospheric degradation processes such as reactions with ozone, $\mathrm{NO}_{3}$ and sunlight-induced photolysis are considered to be of minor importance.

The atmospheric chemistry of esters has been subject to numerous investigations [2]. However, the reactivity of some esters are still not well investigated such as those targeted by the present study. In this work, the rate coefficients for the reactions of $\mathrm{OH}$ and $\mathrm{Cl}$ with four esters are reported:

$$
\text { isopropyl formate: } \quad \mathrm{HC}(\mathrm{O}) \mathrm{OCH}\left(\mathrm{CH}_{3}\right)_{2}+\mathrm{OH} / \mathrm{Cl} \rightarrow \text { products }
$$


isobutyl formate: $\quad \mathrm{HC}(\mathrm{O}) \mathrm{OCH}_{2} \mathrm{CH}\left(\mathrm{CH}_{3}\right)_{2}+\mathrm{OH} / \mathrm{Cl} \rightarrow$ products

n-propyl isobutyrate: $\quad\left(\mathrm{CH}_{3}\right)_{2} \mathrm{CHC}(\mathrm{O}) \mathrm{OC}_{3} \mathrm{H}_{7}+\mathrm{OH} / \mathrm{Cl} \rightarrow$ products

isopropyl isobutyrate: $\left(\mathrm{CH}_{3}\right)_{2} \mathrm{CHC}(\mathrm{O}) \mathrm{OCH}\left(\mathrm{CH}_{3}\right)_{2}+\mathrm{OH} / \mathrm{Cl} \rightarrow$ products $\quad(4 \mathrm{a} / 4 \mathrm{~b})$

In addition, we have conducted a limited number of experiments to identify some products of the $\mathrm{OH}$-initiated oxidation of isopropyl formate, isobutyl formate and n-propyl isobutyrate.

To the best of our knowledge, this work provides the first kinetic studies for the reactions of $\mathrm{OH}$ and $\mathrm{Cl}$ with isobutyl formate and n-propyl isobutyrate and the first studies for the reaction of $\mathrm{Cl}$ with isobutyl formate, propyl isobutyl formate and isopropyl isobutyrate. The reaction of $\mathrm{OH}$ with isopropyl isobutyrate has been investigated previously only once [3]. The most investigated compound of the series of interest for this work is isopropyl formate but only three groups have studied its kinetics [3-5]. The present work reports also the first temperature dependence study for the reactions of these esters with $\mathrm{OH}$ radicals.

\section{EXPERIMENTAL}

\subsection{Relative rate method}

This method was used to measure the rate coefficients for both $\mathrm{Cl}$ and $\mathrm{OH}$ reactions with esters at $296 \pm 2 \mathrm{~K}$ and 760 Torr of purified air in a $160 \mathrm{~L}$ Teflon reaction chamber. The experimental set-up has been described previously [6]. OH radicals were produced through the photolysis of $\mathrm{H}_{2} \mathrm{O}_{2}$ at $254 \mathrm{~nm}$ and $\mathrm{Cl}$ atoms through the photolysis of $\mathrm{Cl}_{2}$ at $365 \mathrm{~nm}$. Measured amounts of reactants were expanded into the evacuated vacuum line and isolated into a calibrated mixing bulb, from which they were swept into the reaction chamber by a 
stream of zero-grade air. The chamber was then filled to its full capacity at atmospheric pressure with ultra-pure air. A gas chromatograph-flame ionization detector was used for the quantitative analysis of the reactants. Chromatographic separation was achieved using a DB1 capillary column (J\&W Scientific, $30 \mathrm{~m}, 0.25 \mathrm{id}, 5 \mu \mathrm{m}$ film).

The relative rate coefficients were determined by comparing the decay rates of the reactants to reference compounds for which the reactions rate coefficients are well established:

$$
\begin{array}{ll}
\mathrm{OH} / \mathrm{Cl}+\text { ester } \rightarrow \text { products } & \mathrm{k}_{\text {ester }} \\
\mathrm{OH} / \mathrm{Cl}+\text { reference } \rightarrow \text { products } & \mathrm{k}_{\text {Ref }}
\end{array}
$$

Provided that both ester and reference compound are lost only by reaction with $\mathrm{OH}$ or $\mathrm{Cl}$, neither organic is reformed in any process and dilution due to sampling is negligible, it can be shown that:

$$
\ln \left([\text { Ester }]_{0} /[\text { Ester }]_{\mathrm{t}}\right)=\left(\mathrm{k}_{\text {ester }} / \mathrm{k}_{\text {Ref }}\right) \ln \left([\text { Ref }]_{0} /[\text { Ref }]_{\mathrm{t}}\right)
$$

where $[\text { Ester }]_{0},[\text { Ester }]_{\mathrm{t}}$ and $[\operatorname{Ref}]_{0}, \quad[\operatorname{Ref}]_{\mathrm{t}}$ are the ester and reference compound concentrations at time 0 and $t$, respectively. $\mathrm{k}_{\mathrm{ester}}$ are the second-order rate coefficients for the reactions of $\mathrm{OH}$ or $\mathrm{Cl}$ with the studied esters, likewise $\mathrm{k}_{\mathrm{Ref}}$ are those for the reactions of $\mathrm{OH}$ or $\mathrm{Cl}$ with the reference compounds. Thus, a plot of $\ln \left([\text { Ester }]_{0} /[\text { Ester }]_{\mathrm{t}}\right)$ vs. $\ln \left([\operatorname{Ref}]_{0} /[\operatorname{Ref}]_{\mathrm{t}}\right)$ should be a straight line passing through the origin. The ratio of rate coefficients $\mathrm{k}_{\mathrm{Ester}} / \mathrm{k}_{\mathrm{Ref}}$.is derived from the slope of this plot.

The rate coefficients for the reactions of $\mathrm{OH}$ with the four esters were obtained relative to that of $\mathrm{OH}$ with propane and pentane. The concentrations of esters and the reference 
compounds were in the range of $40-90 \mathrm{ppm}\left(1 \mathrm{ppm}=2.46 \times 10^{13}\right.$ molecule $\left.\mathrm{cm}^{-3}\right)$ and that of $\mathrm{H}_{2} \mathrm{O}_{2}$ was in the range $200-250 \mathrm{ppm}$. The gas mixtures (esters + references $+\mathrm{H}_{2} \mathrm{O}_{2}$ ) were stable in the dark when left in the chamber for about $2 \mathrm{~h}$. Moreover, no photolysis of esters or references were observed when these compounds were irradiated at $254 \mathrm{~nm}$ in air for about 2h. The measurements of the decays of the reactants in the presence of $\mathrm{OH}$ were conducted for a typical time of $2-2.5 \mathrm{~h}$.

The rate coefficients for the reactions of $\mathrm{Cl}$ atoms with the esters were obtained relative to those of $\mathrm{Cl}$ with ethane and propane. The concentrations of $\mathrm{Cl}_{2}$ and reactants were in the range $(55-132 \mathrm{ppm})$ and $(34-67 \mathrm{ppm})$, respectively. Neither dark reactions (in presence and absence of $\mathrm{Cl}_{2}$ ) nor photolysis (at $365 \mathrm{~nm}$ ) of reagents were observed during the tests. The kinetic measurements were carried out during a photolysis time of $2-3 \mathrm{~h}$ of the reactants mixtures.

\subsection{Absolute rate method}

The pulsed laser photolysis-laser induced fluorescence (PLP-LIF) technique used for measurements is described in a previous publication [7]. Therefore, only a brief description of this system is given here.

$\mathrm{OH}$ radicals were generated by photolysis of $\mathrm{H}_{2} \mathrm{O}_{2}$ at $\lambda=248 \mathrm{~nm}$ and the concentration monitored by pulsed LIF at various reaction times, ranging from $50 \mu$ s to $20 \mathrm{~ms}$. A Nd:YAG pumped frequency-doubled dye laser was used to excite the $\mathrm{OH}$ radical at $\lambda=282 \mathrm{~nm}$. The induced fluorescence was detected by a photomultiplier tube fitted with a $309 \mathrm{~nm}$ narrow 
bandpass filter. The integrated signals from 8 to 14 delay times from 100 probe laser shots were averaged to generate $\mathrm{OH}$ concentration-time profiles over at least three lifetimes. Heated water or cooled ethanol was circulated through the reaction cell jacket to regulate the temperature with an accuracy of $\pm 1 \mathrm{~K} . \mathrm{H}_{2} \mathrm{O}_{2}$ was introduced into the reaction cell by passing a small flow of helium through a glass bubbler containing a solution of $\mathrm{H}_{2} \mathrm{O}_{2}$. Esters were premixed with helium in a $10 \mathrm{~L}$ glass bulb to form a $(0.39-1.58) \%$ mixture at a total pressure of around 900 Torr. The gas mixture containing the ester, $\mathrm{H}_{2} \mathrm{O}_{2}$, and helium as bath gas were flowed through the cell with a linear velocity ranging between 3 and $10 \mathrm{~cm} \mathrm{~s}^{-1}$. The concentration of the esters, ranged from 0.12 to $13.16 \times 10^{14}$ molecule $\mathrm{cm}^{-3}$, was calculated from the mass flow rates, temperature, and pressure in the reaction cell.

All the experiments were conducted under pseudo-first-order conditions with [ester $]_{0}>100$ $[\mathrm{OH}]_{0}$. The initial $\mathrm{OH}$ concentration $\left([\mathrm{OH}]_{0}\right)$ was in the range $(3-32) \times 10^{10}$ molecule $\mathrm{cm}^{-3}$. Thus, the $\mathrm{OH}$ concentration-time profiles followed a simple exponential rate law:

$$
[\mathrm{OH}]_{\mathrm{t}}=[\mathrm{OH}]_{0} \mathrm{e}^{-\mathrm{k}^{\prime} \mathrm{t}} \quad \text { where } \mathrm{k}^{\prime}=\mathrm{k}_{\mathrm{i}}[\text { ester }]+\mathrm{k}^{\prime}{ }_{0}
$$

where $\mathrm{k}_{\mathrm{i}}$ refers to the rate ceofficient for the reation of $\mathrm{OH}$ with the ester and $\mathrm{k}_{0}{ }_{0}$ is the firstorder $\mathrm{OH}$ decay rate in the absence of the ester. The second order rate coefficient $\left(\mathrm{k}_{\mathrm{i}}\right)$ is then obtained by plotting the pseudo-first-order rate coefficient versus the concentration of the ester.

\subsection{Reaction products}


A limited number of runs was carried out using the ICARE-CNRS $7300 \mathrm{~L}$ Teflon chamber and the same experimental procedure described previously [8]. The chamber is surrounded by a set of 28 black lamps for UV light centred at $360 \mathrm{~nm}$. The runs were performed at $296 \pm 2 \mathrm{~K}$ and 760 Torr total pressure of purified air ( $<5 \%$ of relative humidity). Reactants were introduced into the chamber either via the liquid phase by streaming purified air through the liquid sample or as a gas using a calibrated cylinder equipped with two pressure sensors. Rapid mixing of reactants was ensured within 1-2 min using a set of two fans made of Teflon fitted into the chamber. After each experiment, the chamber was flushed with purified air for at least $12 \mathrm{~h}$.

The reactants and products were analyzed by a in situ Fourier transform infrared absorption spectroscopy coupled to a white-type mirror system with an optical path of about 129 m; spectra were recorded every 5 minutes by co-adding $110-120$ scans with a resolution of $1 \mathrm{~cm}^{-1}$. Simultaneously, the samples were quantitatively monitored by GC- PID and GC-MS. For GCPID, reactants and products were separated on a capillary column (SE-30 20m $\times 0.5 \mathrm{~mm}$ i.d.), while for GC-MS, the on-line sampler employed an operating mode of the Turbomatrix in which a sample was collected directly onto the cold trap $\left(-30^{\circ} \mathrm{C}\right)$ and then transferred to the GC and separated on a HP-INNOWAX capillary column $(30 \mathrm{~m} \times 0.25 \mathrm{~mm}$ i.d, $0.25 \mu \mathrm{m}$ film thickness). The column temperature was $40{ }^{\circ} \mathrm{C}$ for GC-PID and $300{ }^{\circ} \mathrm{C}$ for GC-MS. OH radicals were generated by photolysis of $\mathrm{CH}_{3} \mathrm{ONO}$ at $365 \mathrm{~nm}$ in the presence of excess NO. Methyl nitrite was prepared by drop-wise addition of $50 \% \mathrm{H}_{2} \mathrm{SO}_{4}$ to a mixture of $\mathrm{NaNO}_{2}$ and 
methanol. At least three runs were performed for each reaction. The resulting formation yields of gas-phase products arising from each experiment were then averaged, leading to the final gas-phase product yields. The quoted error on the yield values originates from one standard deviation $(1 \sigma)$ on the averaged yield.

\subsection{Materials}

Helium (UHP certified to >99.9995\%), synthetic air (>99.995\%), $\mathrm{Cl}_{2}$ (99.5\%), ethane (>99.5\%) and propane (>99.5\%) were from Air Liquide. Pentane (>99.5\%), isopropyl formate ( $\geq 99.5 \%)$, isobutyl formate $(\geq 99 \%)$, n-propyl isobutyrate ( $\geq 99 \%)$, isopropyl isobutyrate $(\geq 99 \%)$ and hydrogen peroxide $\left(\mathrm{H}_{2} \mathrm{O}_{2}, 50\right.$ wt.\%) were from Sigma-Aldrich. The chemicals were purified by repeated freeze, pump, and thaw cycles and fractional distillation before use. The $\mathrm{H}_{2} \mathrm{O}_{2}$ solution was concentrated by bubbling helium through the solution to remove water for several days prior use and constantly during the course of the experiments.

\section{RESULTS AND DISCUSSION}

\subsection{Relative rate study}

Figure 1 shows examples of the obtained relative loss plots of $\ln \left([\mathrm{ester}]_{O} /[\mathrm{ester}]_{t}\right)$ vs. $\ln \left([\text { reference }]_{o} /[\text { reference }]_{t}\right)$ in presence of $\mathrm{OH}$ and $\mathrm{Cl}$. These plots were linear with intercepts close to zero. Ester and reference concentrations, slopes of $\mathrm{k}_{\text {ester }} / \mathrm{k}_{\text {ref }}$, together with the rate coefficients for ester with $\mathrm{OH}$ obtained are listed in Table 1. The rate coefficients values for $\mathrm{OH}$ reactions with propane and n-pentane used as references were taken from the recommendation [9]: $\mathrm{k}_{(\mathrm{OH}+\text { propane })}=1.1 \times 10^{-12}$ and $\mathrm{k}_{(\mathrm{OH}+\text { pentane })}=3.96 \times 10^{-12} \mathrm{~cm}^{3}$ molecule $\mathrm{s}^{-1}$. 
The rate coefficients obtained by averaging the values from different experiments (two runs for each reaction) are (in $\mathrm{cm}^{3}$ molecule $\left.\mathrm{s}^{-1}\right)$ :

$$
\begin{aligned}
& \mathrm{k}_{1 \mathrm{a}}=(2.0 \pm 0.4) \times 10^{-12} \\
& \mathrm{k}_{2 \mathrm{a}}=(3.4 \pm 0.7) \times 10^{-12} \\
& \mathrm{k}_{3 \mathrm{a}}=(4.9 \pm 1.0) \times 10^{-12} \\
& \mathrm{k}_{4 \mathrm{a}}=(6.1 \pm 1.2) \times 10^{-12}
\end{aligned}
$$

The rate coefficients for reaction of $\mathrm{Cl}$ with the esters investigated in this study were obtained relative to $\mathrm{k}_{(\mathrm{Cl}+\text { ethane })}=(5.9 \pm 0.8) \times 10^{-11}$ and $\mathrm{k}_{(\mathrm{Cl}+\text { propane })}=(1.4 \pm 0.2) \times 10^{-10}$ [9]. The individual rate coefficient ratios $\left(\mathrm{k}_{\mathrm{Ester}} / \mathrm{k}_{\mathrm{Ref}}\right)$ determined for each experiment are listed in Table 1 together with the values of the rate coefficients for the reactions of $\mathrm{Cl}$ with esters derived. The obtained rate coefficients values are (in $\mathrm{cm}^{3}$ molecule $\mathrm{s}^{-1}$ ):

$$
\begin{aligned}
& \mathrm{k}_{1 \mathrm{~b}}=(1.4 \pm 0.2) \times 10^{-11} \\
& \mathrm{k}_{2 \mathrm{~b}}=(7.6 \pm 1.1) \times 10^{-11} \\
& \mathrm{k}_{3 \mathrm{~b}}=(11.2 \pm 1.8) \times 10^{-11} \\
& \mathrm{k}_{4 \mathrm{~b}}=(8.1 \pm 1.2) \times 10^{-11}
\end{aligned}
$$

The errors quoted above are a combination of the $2 \sigma$ statistical errors from the linear analysis plus the error given in the recommended values of the rate coefficients for the reference reactions.

\subsection{Absolute rate study}


Using the PLP-LIF technique, the rate coefficients $\mathrm{k}_{1 \mathrm{a}}-\mathrm{k}_{4 \mathrm{a}}$ were determined in the temperature range $243-373 \mathrm{~K}$. The $\mathrm{OH}$ decays were found to be exponential over at least three lifetimes. $\mathrm{k}_{0}$ was typically in the range of $50-250 \mathrm{~s}^{-1}$, and the values of $\mathrm{k}^{\prime}$ were in the ranges of $189-1995,287-3203,283-3243$ and $781-5024 \mathrm{~s}^{-1}$ for isopropyl formate, isobutyl formate, n-propyl isobutyrate and isopropyl isobutyrate, respectively. The summary of the experimental conditions and the rate coefficients values are given in Table 2.

Figure 2 shows the temperature dependence of the rate coefficients obtained in the Arrhenius forms ( $\mathrm{k}$ vs. 1000/T). The corresponding Arrhenius expressions obtained are (in $\mathrm{cm}^{3}$ molecule $\left.\mathrm{s}^{-1}\right)$ :

$$
\begin{array}{ll}
\mathrm{k}_{1 \mathrm{a}}=(2.76 \pm 0.63) \times 10^{-13} \exp [(571 \pm 66) / \mathrm{T}] & \mathrm{T}=243-373 \mathrm{~K} \\
\mathrm{k}_{2 \mathrm{a}}=(8.38 \pm 1.08) \times 10^{-13} \exp [(398 \pm 38) / \mathrm{T}] & \mathrm{T}=243-373 \mathrm{~K} \\
\mathrm{k}_{3 \mathrm{a}}=(14.81 \pm 9.57) \times 10^{-13} \exp [(347 \pm 214) / \mathrm{T}] & \mathrm{T}=273-373 \mathrm{~K} \\
\mathrm{k}_{4 \mathrm{a}}=(9.99 \pm 3.19) \times 10^{-13} \exp [(534 \pm 94) / \mathrm{T}] & \mathrm{T}=253-373 \mathrm{~K}
\end{array}
$$

The uncertainties for the Arrhenius parameters $\mathrm{A}$ and $\mathrm{E} / \mathrm{R}$ are given by $\Delta \mathrm{A}=2 \mathrm{~A} \sigma_{\ln \mathrm{A}}$ and $\Delta \mathrm{E} / \mathrm{R}=2 \sigma_{\mathrm{E} / \mathrm{R}}$, respectively.

The room temperature rate coefficients, $\mathrm{k}_{1 \mathrm{a}}-\mathrm{k}_{4 \mathrm{a}}$, taken as the average of all values obtained at $(298 \pm 1) \mathrm{K}$ are $\left(\right.$ in $10^{-12} \mathrm{~cm}^{3}$ molecule $\left.\mathrm{s}^{-1}\right): \mathrm{k}_{1 \mathrm{a}}=(1.87 \pm 0.11), \mathrm{k}_{2 \mathrm{a}}=(3.17 \pm 0.20), \mathrm{k}_{3 \mathrm{a}}=(4.59$ $\pm 0.53)$ and $\mathrm{k}_{4 \mathrm{a}}=(5.87 \pm 0.39)$. These values are in good agreement with those obtained by the relative method.

\subsection{Reaction products study}


Using FTIR, GC-MS and GC-PID analysis methods, the products from OH-initiated oxidation of isopropyl formate, isobutyl formate and n-propyl isobutyrate were investigated but under limited conditions. Due to the lack of IR reference spectra of unknown products, only few reaction products have been detected and quantified mainly by GC-MS and GC-PID. Acetone was observed as product in the three reactions. Figures 3 and 4 show the plots of the acetone formation vs. the loss of the esters. The formation yields of acetone obtained by GCMS and GC-PID were in agreement leading to $39 \pm 2 \%$ for isopropyl formate, $43 \pm 2 \%$

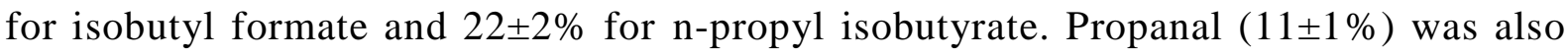
observed as product in the reaction of $\mathrm{OH}$ with $\mathrm{n}$-propyl isobutyrate.

\section{Discussion}

\section{Comparison with literature:}

Cl reactions: There are no prior experimental values for the rate coefficients for the reaction of $\mathrm{Cl}$ with the esters studied except for isopropyl formate. Using the relative rate method and $\mathrm{CH}_{3} \mathrm{OH}\left(\mathrm{k}\left(\mathrm{Cl}+\mathrm{CH}_{3} \mathrm{OH}\right)=5.5 \times 10^{-11} \mathrm{~cm}^{3}\right.$ molecule $\left.\mathrm{s}^{-1}\right)$, Pimentel et al. [5] obtained a ratio $\mathrm{k}_{(\mathrm{Cl}+\text { isopropyl formate })} / \mathrm{k}_{(\mathrm{Cl}+\mathrm{CH} 3 \mathrm{OH})}=0.32 \pm 0.03$ from which they derived the value $\mathrm{k}(\mathrm{Cl}+$ isopropyl formate $)=(1.75 \pm 0.35) \times 10^{-12} \mathrm{~cm}^{3}$ molecule $\mathrm{s}^{-1}$ at $296 \mathrm{~K}$. The value obtained in the present work, $\mathrm{k}=(1.4 \pm 0.2) \times 10^{-11}$, is in good agreement with that from Pimentel et al.

$\mathrm{OH}$ reactions: The literature survey shows that only a limited number of studies have been dedicated to the esters investigated in the present work. The only available data are those for $\mathrm{OH}$ reaction with isopropyl formate from Stemmler et al. [3] $\left(\mathrm{k}=(2.2 \pm 0.2) \times 10^{-12}\right.$, placed on 
absolute basis using $\mathrm{k}\left(\mathrm{n}-\mathrm{C}_{3} \mathrm{H}_{7}\right)_{2} \mathrm{O}=2.0 \times 10^{-11}$ [2] $)$, Szilagyi et al. [4] $\left(\mathrm{k}=(1.87 \pm 0.08) \times 10^{-12}\right.$, using flow discharge flow tube-resonance fluorescence technique) and Pimentel et al. [5] (k $=(2.37 \pm 0.40) \times 10^{-12}$, placed on absolute basis using $\mathrm{k}\left(\mathrm{C}_{2} \mathrm{H}_{4}\right)=7.9 \times 10^{-12}$ [10]. Pimentel et al. have also reported the rate coefficient for the reaction of $\mathrm{OH}$ isopropyl isobutyrate $(\mathrm{k}=$ $(7.0 \pm 0.4) \times 10^{-12}$ placed on absolute basis using $\mathrm{k}\left(\mathrm{n}-\mathrm{C}_{3} \mathrm{H}_{7}\right)_{2} \mathrm{O}=2.0 \times 10^{-11}$ taken from Calvert et al. [2]). Hence, this work presents the first kinetic measurements for the reactions of $\mathrm{OH}$ with isobutyl formate and n-propyl isobutyrate. Further, we report here the first absolute measurements of the rate coefficients for the reactions of $\mathrm{OH}$ with isobutyl formate, propyl isobutyrate and isopropyl isobutyrate. This is the first temperature dependence study for the four reactions. The values determined here for isopropyl formate and isopropyl isobutyrate agree reasonably well with previous measurements. The values obtained by both absolute and relative methods are in good agreement as shown in Table 3.

\section{Reactivity Trends:}

Examination of the reactivity of the esters towards $\mathrm{OH}$ radicals shows some trends depending on the esters molecular structure. Comparison of the room temperature rate coefficients shows an increase of the $\mathrm{OH}$ reactivity with the increase of the chain length in the linear esters: formates (methyl formate (0.179), ethyl formate (0.87), n-propyl formate (1.85) and n-butyl formate (3.68)); acetates (methyl acetate (0.346), ethyl acetate (1.67), n-propyl acetate (3.45), n-butyl acetate (5.66) and n-pentyl acetate (7.39)); propionates (methyl propionate (0.873), ethyl propionate (2.1) and n-propyl propionate (4.2)) and butyrates (methyl butyrate (3.36), 
ethyl butyrate (4.5), n-propyl butyrate (4.71) and n-butyl butyrate (10.6) (in $10^{-12} \mathrm{~cm}^{3}$ molecule $\left.\mathrm{e}^{-1} \mathrm{~s}^{-1}\right)[2,11,12]$. The observed increase in the reactivity is due to the contribution of the alkoxy side of the ester $(-\mathrm{C}(\mathrm{O}) \mathrm{OR})$ as the reaction coefficient value increases with the increase of the number of $-\mathrm{CH}_{2}$ - groups, consistent with hydrogen atom abstraction by $\mathrm{OH}$ from the -OR group.

The present work brings additional information on the reactivity of formates through the new measurement of $\mathrm{k}(\mathrm{OH}+\mathrm{isobutyl}$ formate $)$ reported here for the first time. The rate coefficients for the reactions of $\mathrm{OH}$ with isobutyl formate and n-butyl formate are similar, $3.3 \times 10^{-12}$ and $3.68 \times 10^{-12}$, respectively, but much higher than $\mathrm{k}(\mathrm{OH}+$ tert-butyl formate $)=0.78 \times 10^{-12}\left(\mathrm{in}^{3}\right.$ molecule $\mathrm{s}^{-1}$ ). The same observation can be made for the reactivities of $\mathrm{OH}$ with n-butyl, isobutyl and tert-butyl acetates, $\mathrm{k}_{\mathrm{OH}}=5.66,6.47,0.57 \times 10^{-12} \mathrm{~cm}^{3}$ molecule $\mathrm{s}^{-1}$ [2]. No data are available for the same series of propionates and butyrates in order to make a comparison. Similarly, the reactivities of n-propyl isobutyrate and isopropyl isobutyrate towards $\mathrm{OH}$ are also in the same order of magnitude (within $30 \%$ ), $4.7 \times 10^{-12}$ and $6.0 \times 10^{-12}$, respectively. These comparable reactivities are also observed for formates $(\mathrm{k}$ ( $\mathrm{n}$-propyl formate $)=1.85 \times 10^{-}$ 12 and $\mathrm{k}($ iso-propyl formate $\left.)=2.29 \times 10^{-12}\right)$ and acetates $\left(\mathrm{k}(\mathrm{n}\right.$-propyl acetate $)=3.45 \times 10^{-12}$ and $\mathrm{k}($ iso-propyl acetate $\left.)=3.79 \times 10^{-12}\right)$. These observations may indicate a comparable reactivity schemes between the above esters towards $\mathrm{OH}$ radicals. Products studies can provide clearer information about the mechanisms through which these reactions proceed. 
Comparison was made with the data obtained using the SAR of Kwok and Atkinson [13] and the substituent factors they have proposed $\left(\mathrm{F}(-\mathrm{C}(\mathrm{O}) \mathrm{OR})=0.74, \quad \mathrm{~F}\left(-\mathrm{OC}(\mathrm{O}) \mathrm{R}^{\prime}\right)=1.6, \mathrm{~F}(-\right.$ $\mathrm{C}(\mathrm{O}) \mathrm{OH})=1.6$ and $\left.\mathrm{F}\left(-\mathrm{CH}_{2}-\mathrm{C}(\mathrm{O}) \mathrm{OR}\right)=1.23\right)$ as well as with the updated ones from Le Calvé et al. [14]: $\mathrm{F}(-\mathrm{C}(\mathrm{O}) \mathrm{OR})=0.74, \mathrm{~F}\left(-\mathrm{OC}(\mathrm{O}) \mathrm{R}^{\prime}\right)=1.6, \mathrm{~F}(-\mathrm{C}(\mathrm{O}) \mathrm{OH})=0.6$ and $\mathrm{F}\left(-\mathrm{CH}_{2}-\mathrm{C}(\mathrm{O}) \mathrm{OR}\right)=2.2$. A fair agreement is obtained between the experimental values and the calculated ones for the isobutyrates (n-propyl isobutyrate: $\mathrm{k}_{\exp }=4.75, \mathrm{k}_{\text {calSAR }}=4.92, \mathrm{k}_{\text {SARupdated }}=5.19$ and isopropyl isobutyrate: $\mathrm{k}_{\mathrm{exp}}=5.99, \mathrm{k}_{\text {calSAR }}=5.21, \mathrm{k}_{\mathrm{SARupdated}}=5.47 \times 10^{-12}$ ). The updated SAR [14] shows a better agreement with the experimental data for the formates while the substituent factors from Kwok and Atkinson lead to higher values (isopropyl formate: $\mathrm{k}_{\mathrm{exp}}=1.99$, $\mathrm{k}_{\mathrm{calSAR}}=3.44$, $\mathrm{k}_{\text {SARupdated }}=1.61$ and isobutyl formate: $\mathrm{k}_{\text {exp }}=3.28, \mathrm{k}_{\text {calSAR }}=4.56, \mathrm{k}_{\text {SARupdated }}=3.52 \times 10^{-12}$ $\mathrm{cm}^{3}$ molecule $\left.\mathrm{s}^{-1}\right)$.

Negative temperature dependence of the rate coefficient of $\mathrm{OH}$ reaction with esters observed in this work has been reported previously $[2,12]$. It is presumed that this near-zero or negative temperature dependence of the rate coefficients for reactions of $\mathrm{OH}$ could be partly attributed to an alternative channel in parallel to the direct $\mathrm{H}$-atom abstraction occurring through formation of an adduct which decomposes to products.

\section{Reactions products:}

The OH-initiated oxidation of isopropyl formate has been extensively studied by Pimentel et al. [5]. Isobutyl formate and n-propyl isobutyrate have not been studied previously. The investigation of the $\mathrm{OH}$-initiated oxidation of isopropyl formate by Pimentel et al. 
showed the formation of formic acid $(\mathrm{HC}(\mathrm{O}) \mathrm{OH}, 15-20 \%)$ and acetic formic anhydride (AFAN, $\mathrm{CH}_{3} \mathrm{C}(\mathrm{O}) \mathrm{OC}(\mathrm{O}) \mathrm{H}, 43 \%$ ) in addition to acetone (43\%). By comparing the products yields they obtained in both the $\mathrm{Cl}$ and $\mathrm{OH}$-initiated oxidation of isopropyl formate (same set of products but different yields) and suggested that the reaction of $\mathrm{OH}$ proceeds mainly through abstraction from the tertiary site (>CH-O-) with an estimated contribution of $55-65 \%$ to the overall reaction. The contribution of abstraction from the $\mathrm{C}(\mathrm{O}) \mathrm{H}$ group was estimated to be $20-25 \%$. Based on these observations, one can postulate that the reaction of $\mathrm{OH}$ with isobutyl formate will proceed at least partly through the same scheme. In addition to the $\mathrm{H}$-atom abstraction from tertiary site $(>\mathrm{CH}-)$ and $\mathrm{C}(\mathrm{O}) \mathrm{H}$ group, there will be an abstraction from the $-\mathrm{CH}_{2}$ - group. Hence, an additional set of products such as $\mathrm{H}(\mathrm{O}) \mathrm{COC}(\mathrm{O}) \mathrm{H}$ could be formed following this later channel. The reaction of $\mathrm{OH}$ with $\mathrm{n}$-propyl isobutyrate $\left(\left(\mathrm{CH}_{3}\right)_{2} \mathrm{CHC}(\mathrm{O}) \mathrm{OC}_{3} \mathrm{H}_{7}\right)$ may occur through the $\mathrm{H}$-atom abstraction from both $(>\mathrm{CH}-)$ and $\left(-\mathrm{OC}_{3} \mathrm{H}_{7}\right)$ groups. The acetone formed from the $\mathrm{OH}$-initiated oxidation of $\mathrm{HC}(\mathrm{O}) \mathrm{OCH}_{2} \mathrm{CH}\left(\mathrm{CH}_{3}\right)_{2}$ and $\left(\mathrm{CH}_{3}\right)_{2} \mathrm{CHC}(\mathrm{O}) \mathrm{OC}_{3} \mathrm{H}_{7}$ is at least partly produced though the $\mathrm{H}$-atom abstraction from (>CH-). Propanal which was observed as product in the reaction of $\mathrm{OH}$ with n-propyl isobutyrate is arising through the $\mathrm{H}$-atom abstraction from the propyl group. Clearly, more detailed mechanistic studies are needed for a better understanding of the reaction routes taking place.

\section{Atmospheric Implications}


Reaction with $\mathrm{OH}$ is expected to be the major loss process of esters in the troposphere, while their reaction with $\mathrm{Cl}$ atoms could constitute an important degradation pathway in coastal areas and the marine boundary layer. The other processes such as reactions with $\mathrm{O}_{3}, \mathrm{NO}_{3}$ and photolysis are expected to be negligible. Tropospheric removal by uptake in surface and rainwater or cloud droplets are also of negligible importance as sinks for these compounds since they are volatile and sparingly soluble in water. Thus, only the present kinetic data for $\mathrm{OH}$ and $\mathrm{Cl}$ reactions were used to estimate the tropospheric lifetimes of the studied esters. Using tropospheric $[\mathrm{OH}]=2 \times 10^{6}$ radicals $\mathrm{cm}^{-3}(12$-h daytime average $[15])$ and $[\mathrm{Cl}]=1 \times 10^{4}$ atoms $\mathrm{cm}^{-3}$ (24-h average [16], the tropospheric lifetimes $(\tau=1 / k[\mathrm{X}]$ with $\mathrm{X}=\mathrm{OH}$ and $\mathrm{Cl})$ with respect to reactions of esters with $\mathrm{OH}$ and $\mathrm{Cl}$ are estimated to be around 1 to 3 days and 10 to 82 days, respectively. These calculations confirm that the daytime $\mathrm{OH}$ reactions constitute the dominant chemical removal pathway for these esters, even if $\mathrm{Cl}$ reactions are not negligible and can be important and ubiquitous in the atmosphere. The relatively short atmospheric lifetimes indicate that these oxygenated compounds will be oxidized rapidly by reaction with $\mathrm{OH}$ near their emission sources to form other atmospheric organic components.

\section{Acknowledgments}

CNNSF (21307121, 41075094, 21177140 and 20977097), Special Fund ERPI (201009001), NBRD Program 973 (2010CB732304), EU Seventh Framework Programmes (FP7/20072013) grant agreement $N^{\circ} 228335$ (EUROCHAMP2) and Marie Curie International Research 
Staff Exchange Scheme Fellowship, Labex Voltaire (ANR-10-LABX-100-01) for support.

Y.J.Z. acknowledges the China Postdoctoral Science Foundation. 


\section{REFERENCES}

[1] J.A. Thornton, J.P. Kercher, T.P. Riedel, N.L. Wagner, J. Cozic, J.S. Holloway, W.P.

Dubé, G.M. Wolfe, P.K. Quinn, A.M. Middlebrook, B. Alexander, S. Brown, Nature, 464 (2010) 271.

[2] J.G. Calvert, A. Mellouki, J.J. Orlando, M.J. Pilling, T.J. Wallington, The mechanisms of atmospheric oxidation of the oxygenates, Oxford University Press, 2011.

[3] K. Stemmler, W. Mengon, J.A. Kerr, J. Chem. Soc. Faraday Trans. 16 (1997) 2865.

[4] I. Szilagyi, Dobe S., Berces T., Marta F., Viskolcz B., Z. Phys. Chem. 218 (2004) 479.

[5] A.S. Pimentel, G. Tyndall, J.J. Orlando, M.D. Hurley, T.J. Wallington, M.S. Andersen, P. Marshall, T.S. Dibble, Int. J. Chem. Kinet. 42 (2010) 479.

[6] R. Thevenet, A. Mellouki, G. Le Bras, Int. J. Chem. Kinet. 32 (2000) 676.

[7] A. Mellouki, S. Téton, G. Le Bras, Int. J. Chem. Kinet. 27 (1995) 791.

[8] F. Bernard, V. Daële, A. Mellouki, H. Sidebottom, J. Phys. Chem. A, 116 (2012) 6113.

[9] J.G. Calvert, R.G. Derwent, J.J. Orlando, G.S. Tyndall, T.J. Wallington, Mechanisms of atmospheric oxidation of the alkanes, Oxford University Press, 2008.

[10] R. Atkinson, D.L. Baulch, R.A. Cox, J.N. Crowley, R. F. Hampson, R.G. Hynes, M.E. Jenkin, M.J. Rossi, J. Troe, Atmos. Chem. Phys. 6 (2006) 3625.

[11] P.M. Cometto, V. Daële, M. Idir, S.L. Lane, A. Mellouki, J. Phys. Chem. A, 113 (2009) 10745.

[12] P. Liang, M.J. Mu, V. Daële, A. Mellouki, Chem Phys Chem, 11 (2010) 4097. 
[13] E.S.C.Kwok, R. Atkinson R., Atmos. Env., 29 (1995) 1685.

[14] S. Le Calvé, G. Le Bras, A. Mellouki , Int. J. Chem. Kin., 29 (1997) 683.

[15] R. Hein R., P.J. Crutzen, M. Heimann, Global Biogeochem. Cycle 11 (1997) 43.

[16] O.W. Wingenter, M.K. Kubo, N.J. Blake, T.W. Smith Jr, D.R. Blake, F.S. Rowland, J. Geophys. Res. 101 (D2) (1996) 4331. 


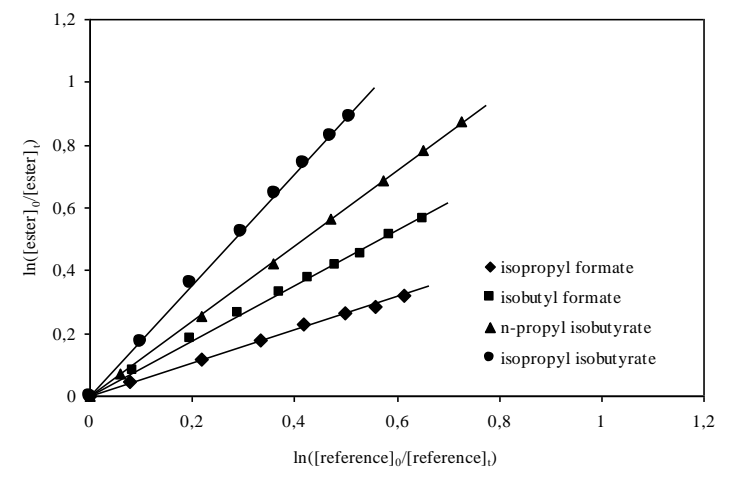

$\mathrm{OH}$ reactions

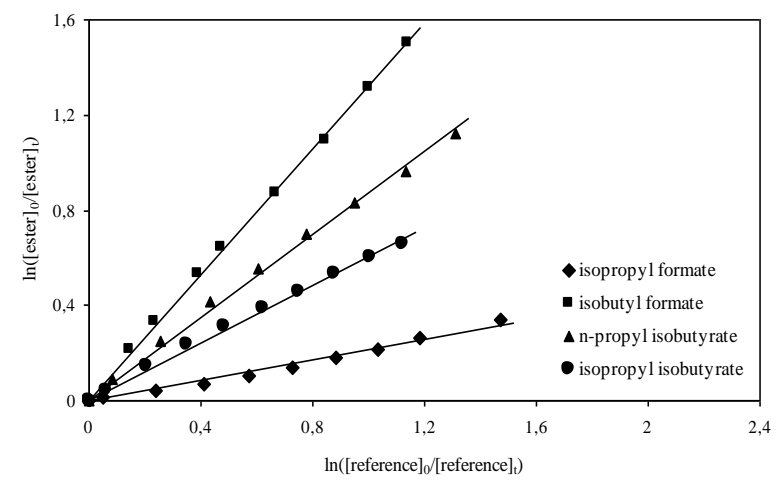

$\mathrm{Cl}$ reactions

Figure 1: Relative rate data for the $\mathrm{OH}$ and $\mathrm{Cl}$ reactions with the studied esters at $296 \mathrm{~K}$ and atmospheric pressure using pentane as reference compound for $\mathrm{OH}$ reactions and ethane for $\mathrm{Cl}$ reactions with isopropyl formate and isobutyl formate and propane for n-propyl isobutyrate and isopropyl isobutyrate. 

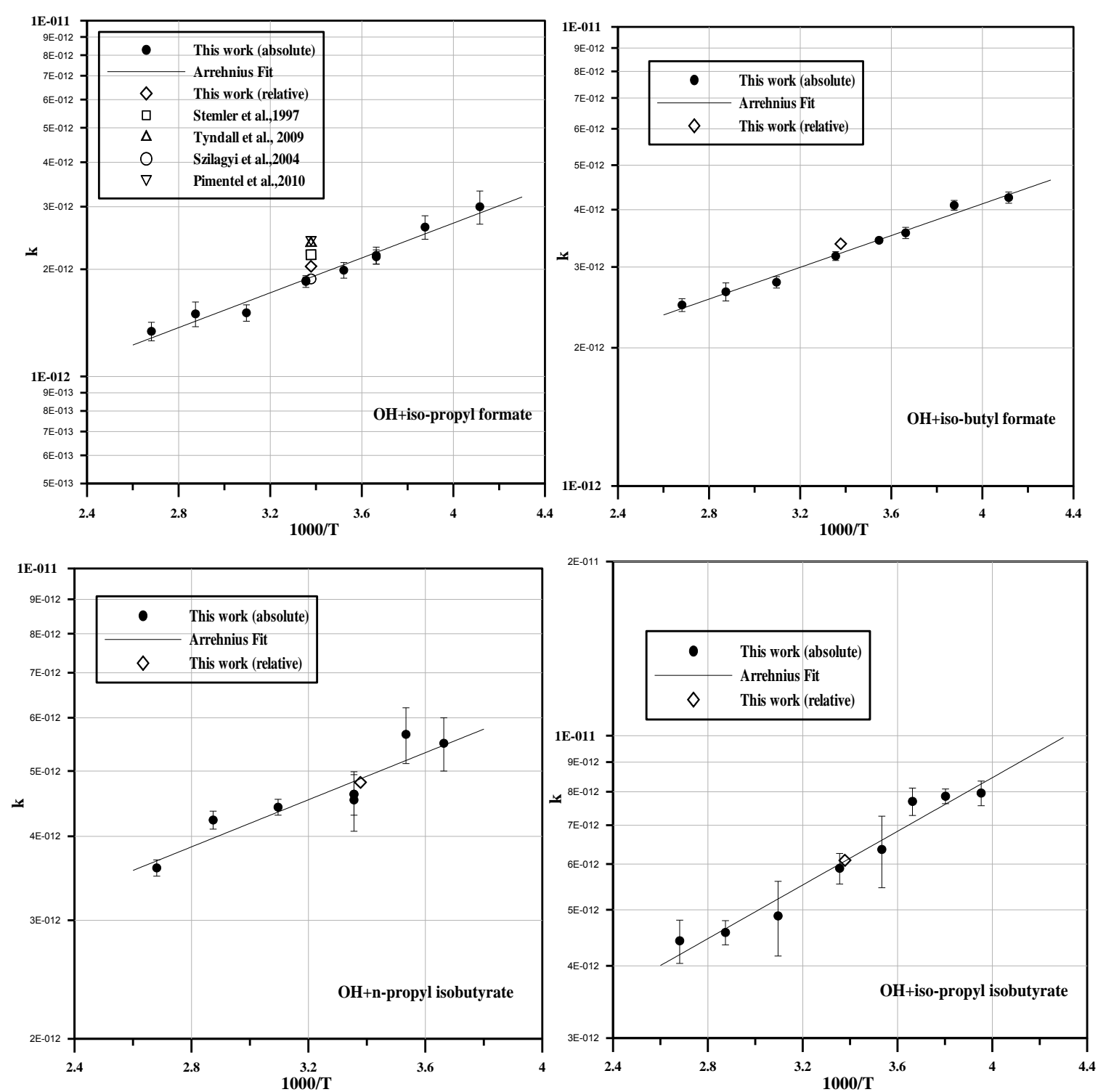

Figure 2: Plots of $\mathrm{k}_{\mathrm{i}}(\mathrm{i}=1 \mathrm{a}-4 \mathrm{a})$ as function of $1000 / \mathrm{T}$ for the $\mathrm{OH}$ reaction with isopropyl formate, isobutyl formate, n-propyl isobutyrate and isopropyl isobutyrate associated with literature data for isopropyl formate (see text). 

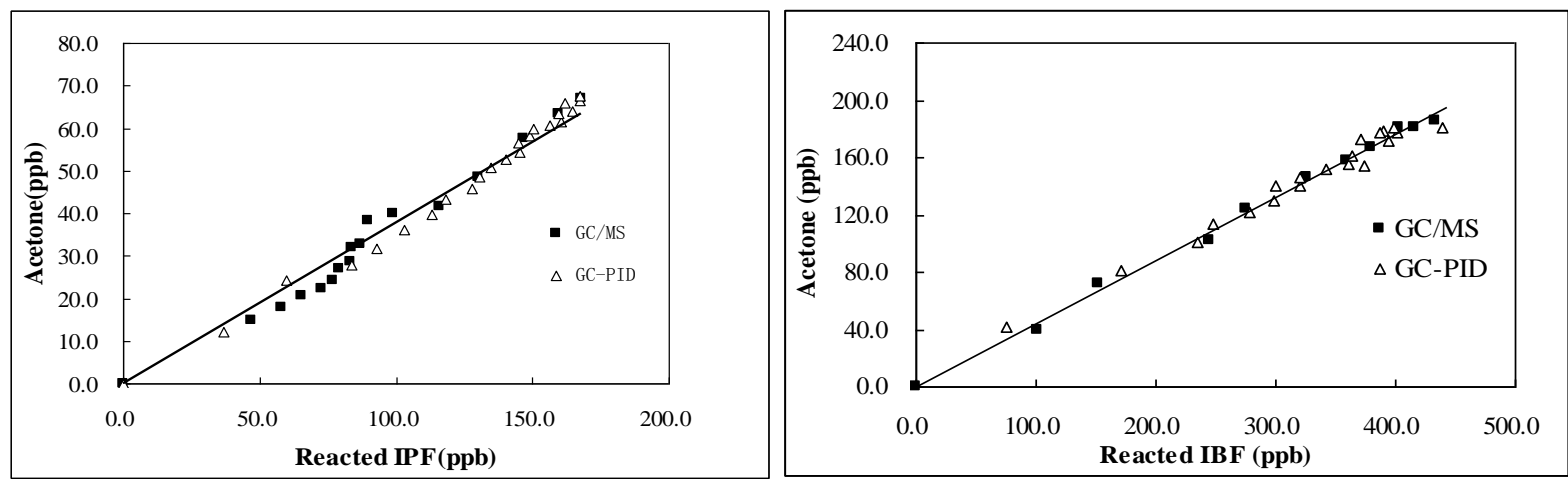

Figure 3: Reactions of $\mathrm{OH}$ with isopropyl formate and isobutyl formate: plots of acetone against consumed fraction of formates obtained by both GC/MS (घ) and GC-PID ( $\Delta$ ).

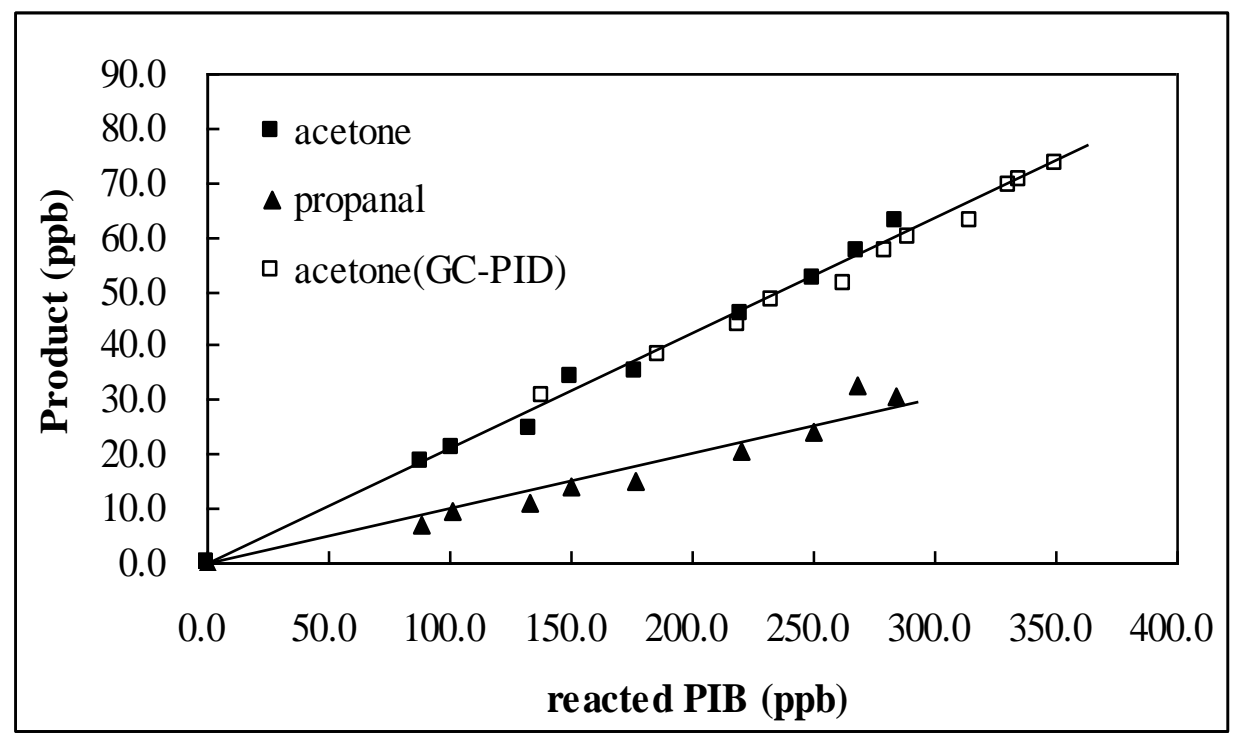

Figure 4: Reaction of $\mathrm{OH}$ with n-propyl isobutyrate: acetone and propanal concentrations versus the consumed fraction of n-propyl isobutyrate obtained by GC/MS ( $\mathbf{n}, \boldsymbol{\Delta})$ and GC-PID $(\square)$. 
Table 1. Rate coefficients ratios, $\mathrm{k}_{\mathrm{ester}} / \mathrm{k}_{\mathrm{ref}}$, and the obtained rate coefficients for the $\mathrm{OH}$ and

$\mathrm{Cl}$ reactions with the studied esters at $(296 \pm 2) \mathrm{K}$ and 760 torr of air.

\begin{tabular}{|c|c|c|c|c|c|}
\hline Ester & {$[\text { Esters }]_{0}(\mathrm{ppm})$} & Reference & {$[\mathrm{Ref}]_{0}(\mathrm{ppm})$} & $\mathrm{k}_{\text {Ester }} / \mathrm{k}_{\text {ref }}{ }^{\mathrm{a}}$ & $\begin{array}{l}\mathrm{k}_{\text {Ester }}\left(10^{-12} \mathrm{~cm}^{3}\right. \\
\left.\text { molecule } \mathrm{e}^{-1} \mathrm{~s}^{-1}\right)^{\mathrm{b}}\end{array}$ \\
\hline \multicolumn{6}{|c|}{ OH reactions } \\
\hline \multirow[t]{2}{*}{ Isopropyl formate } & 55 & Propane & 40 & $1.89 \pm 0.02$ & $2.06 \pm 0.31$ \\
\hline & 62 & Pentane & 90 & $0.51 \pm 0.02$ & $2.02 \pm 0.41$ \\
\hline Isobutyl formate & 59 & Pentane & 83 & $0.85 \pm 0.02$ & $3.37 \pm 0.68$ \\
\hline n-Propyl formate & $40-50$ & Pentane & $46-55$ & $1.23 \pm 0.02$ & $4.87 \pm 0.98$ \\
\hline Isopropyl isobutyrate & $40-56$ & Pentane & $55-67$ & $1.54 \pm 0.02$ & $6.1 \pm 1.2$ \\
\hline \multicolumn{6}{|c|}{ Cl reactions } \\
\hline Isopropyl formate & 67 & Ethane & 62 & $0.24 \pm 0.02$ & $14 \pm 2$ \\
\hline Isobutyl formate & 53 & Ethane & 77 & $1.29 \pm 0.04$ & $76 \pm 11$ \\
\hline n-Propyl formate & $34-51$ & Propane & $34-55$ & $0.80 \pm 0.06$ & $112 \pm 18$ \\
\hline Isopropyl isobutyrate & 51 & Propane & 52 & $0.58 \pm 0.02$ & $81 \pm 12$ \\
\hline
\end{tabular}

${ }^{a}$ The errors quoted correspond to twice the standard deviation arising from the least-squares

fit of the data and do not include the estimated error on the reference rate constant.

${ }^{b}$ The errors quoted are a combination of the $2 \sigma$ statistical errors from the linear analysis plus the error given in the recommended values of the rate coefficients for the reference reactions. 
Table 2. Reactions $\mathrm{OH}+$ the studied esters: summary of experimental conditions and absolute measured rate coefficients.

\begin{tabular}{|c|c|c|c|c|c|c|c|c|}
\hline $\mathrm{T}(\mathrm{K})$ & $\begin{array}{l}\text { [isopropyl formate] } \\
\qquad\left(\times 10^{14}\right)^{\mathrm{a}}\end{array}$ & $\begin{array}{c}\left(\mathrm{k}_{1 \mathrm{a}} \pm 2 \sigma\right)^{\mathrm{b}} \\
\times 10^{12}\end{array}$ & $\begin{array}{c}\text { [isobutyl formate] } \\
\left.\qquad \times 10^{14}\right)^{\mathrm{a}}\end{array}$ & $\begin{array}{c}\left(\mathrm{k}_{2 \mathrm{a}} \pm 2 \sigma\right)^{\mathrm{b}} \\
\times 10^{12}\end{array}$ & $\begin{array}{l}\text { [n-propyl isobutyrate] } \\
\qquad\left(\times 10^{14}\right)^{\mathrm{a}}\end{array}$ & $\begin{array}{c}\left(\mathrm{k}_{3 \mathrm{a}} \pm 2 \sigma\right)^{\mathrm{b}} \\
\times 10^{12}\end{array}$ & $\begin{array}{c}\text { [isopropyl isobutyrate] } \\
\qquad\left(\times 10^{14}\right)^{\mathrm{a}}\end{array}$ & $\begin{array}{c}\left(\mathrm{k}_{4 \mathrm{a}} \pm 2 \sigma\right)^{\mathrm{b}} \\
\times 10^{12}\end{array}$ \\
\hline 243 & $0.52-4.44$ & $3.06 \pm 0.32$ & $1.44-10.21$ & $4.25 \pm 0.46$ & - & - & - & - \\
\hline 253 & - & - & - & - & - & - & $2.47-13.16$ & $7.96 \pm 0.39$ \\
\hline 258 & $0.46-4.19$ & $2.63 \pm 0.20$ & $1.38-7.85$ & $4.09 \pm 0.12$ & - & - & _ & - \\
\hline 263 & - & - & - & - & - & - & $2.36-13.41$ & $7.86 \pm 0.23$ \\
\hline 273 & $0.46-5.01$ & $2.19 \pm 0.12$ & $1.49-10.30$ & $3.56 \pm 0.24$ & $1.22-7.50$ & $5.50 \pm 0.50$ & $2.62-13.05$ & $7.70 \pm 0.42$ \\
\hline 273 & $1.39-9.44$ & $2.17 \pm 0.10$ & - & - & - & - & - & - \\
\hline 283 & $0.52-4.28$ & $1.99 \pm 0.10$ & $1.22-7.51$ & $3.43 \pm 0.14$ & $1.28-7.28$ & $5.67 \pm 0.54$ & $2.22-12.49$ & $6.36 \pm 0.89$ \\
\hline 298 & $0.20-3.62$ & $1.89 \pm 0.10$ & $1.38-10.50$ & $3.17 \pm 0.20$ & $1.27-7.30$ & $4.62 \pm 0.32$ & $2.30-12.54$ & $5.90 \pm 0.36$ \\
\hline 298 & $0.26-4.78$ & $1.86 \pm 0.04$ & - & - & $1.19-6.94$ & $4.53 \pm 0.46$ & $1.73-10.46$ & $5.83 \pm 0.37$ \\
\hline 298 & $1.20-9.99$ & $1.85 \pm 0.07$ & - & - & $1.10-7.62$ & $4.62 \pm 0.52$ & - & - \\
\hline 323 & $0.24-3.94$ & $1.55 \pm 0.08$ & $1.35-9.62$ & $2.78 \pm 0.08$ & $0.89-6.23$ & $4.42 \pm 0.12$ & $1.63-9.30$ & $4.88 \pm 0.72$ \\
\hline 348 & $0.22-4.25$ & $1.50 \pm 0.12$ & $1.21-8.87$ & $2.65 \pm 0.18$ & $1.38-6.58$ & $4.23 \pm 0.13$ & $1.38-7.94$ & $4.57 \pm 0.22$ \\
\hline 373 & $0.33-4.08$ & $1.34 \pm 0.08$ & $1.34-5.99$ & $2.48 \pm 0.28$ & $1.01-6.14$ & $3.59 \pm 0.10$ & $1.17-9.43$ & $4.42 \pm 0.38$ \\
\hline
\end{tabular}

${ }^{\mathrm{a}}$ Units in molecule $\mathrm{cm}^{-3}$. ${ }^{\mathrm{b}}$ Units in $\mathrm{cm}^{3}$ molecule ${ }^{-1} \mathrm{~s}^{-1}$.

The quoted errors given in this table include $2 \sigma$ from the least-squares analysis and do not include the estimated systematic errors. 
Table 3. Summary of $\mathrm{OH}$ reaction rate coefficients and Arrhenius parameters obtained in this work and those from previous determinations.

\begin{tabular}{|c|c|c|c|c|c|c|c|}
\hline \multirow{2}{*}{ Ester } & $\mathrm{T}_{\text {room }}$ & $\mathrm{k}_{\text {Troom }}{ }^{\mathrm{a}}$ & T range & A & $\mathrm{E} / \mathrm{R}$ & \multirow{2}{*}{ Method $^{\mathrm{b}}$} & \multirow{2}{*}{ Ref. } \\
\hline & $(\mathrm{K})$ & $\left(10^{-12} \mathrm{~cm}^{3}\right.$ molecule $\left.^{-1} \mathrm{~s}^{-1}\right)$ & $(\mathrm{K})$ & $\left(10^{-13} \mathrm{~cm}^{3}\right.$ molecule $\left.^{-1} \mathrm{~s}^{-1}\right)$ & $\left(\mathrm{K}^{-1}\right)$ & & \\
\hline \multirow{5}{*}{ isopropyl formate } & 298 & $1.87 \pm 0.11$ & $243-373$ & $2.76 \pm 0.63$ & $-(571 \pm 66)$ & PLP-LIF & \multirow{2}{*}{ This work } \\
\hline & $296 \pm 2$ & $2.1 \pm 0.4$ & - & - & - & $\mathrm{RR}$ & \\
\hline & 296 & $2.2 \pm 0.2^{\mathrm{d}}$ & - & - & - & $\mathrm{RR}$ & [3] \\
\hline & 296 & $1.87 \pm 0.08$ & - & - & - & DF-RF & {$[4]$} \\
\hline & 296 & $2.37 \pm 0.40^{\mathrm{d}}$ & - & - & - & $\mathrm{RR}$ & {$[5]$} \\
\hline \multirow{2}{*}{ isobutyl formate } & 298 & $3.17 \pm 0.20$ & $243-373$ & $8.38 \pm 1.08$ & $-(398 \pm 38)$ & PLP-LIF & \multirow{6}{*}{ This work } \\
\hline & $296 \pm 2$ & $3.4 \pm 0.7$ & - & - & - & $\mathrm{RR}$ & \\
\hline \multirow{2}{*}{$\mathrm{n}$-propyl isobutyrate } & 298 & $4.59 \pm 0.53$ & $298-373$ & $14.81 \pm 9.57$ & $-(347 \pm 214)$ & PLP-LIF & \\
\hline & $296 \pm 2$ & $4.9 \pm 0.9$ & - & - & - & $\mathrm{RR}$ & \\
\hline \multirow{3}{*}{ isopropyl isobutyrate } & 298 & $5.87 \pm 0.39$ & $253-373$ & $9.99 \pm 3.19$ & $-(534 \pm 94)$ & PLP-LIF & \\
\hline & $296 \pm 2$ & $6.1 \pm 1.2$ & - & - & - & $\mathrm{RR}$ & \\
\hline & 298 & $7.0 \pm 0.4^{\mathrm{d}}$ & - & - & - & $\mathrm{RR}$ & [5] \\
\hline
\end{tabular}

${ }^{a}$ Rate coefficients are those reported by Calvert et al. [2] using the recommended values for the reference rate coefficients.

${ }^{\mathrm{b}}$ Key: PLP-LIF, pulsed laser photolysis-laser induced fluorescence; RR, relative rate; DF-RF, discharge flow- resonance fluorescence. 